Kong. Res. J. 1(2): 23-30, 2014

Kongunadu Arts and Science College, Coimbatore

\title{
DYNAMIC PRICING MODEL USING PRICE MULTIPLIERS FOR ONLINE BUS TICKET BOOKING
}

\author{
Sindu, D*. \\ Department of Mathematics, Kongunadu Arts and Science College, Coimbatore - 641029. \\ *E-mail: justmail.sindu@gmail.com
}

\begin{abstract}
Dynamic pricing is a price determination by the buyer and seller at the time of transaction. In the present study we propose a dynamic pricing approach for the online bus ticket booking. The proposed approach is based on having "price multipliers" that vary around " 1 " and provide a varying discount/premium over the base price. The price multipliers are functions of certain influencing variables .The values of price multipliers are determined based on analysis of price multipliers and its demand variation. We have tested the proposed approach by successfully applying it to the online bus ticket booking for the route "Chennai - Mudalur 2012" of Ticketgoose.com, an online bus ticket booking firm as a case study.
\end{abstract}

Keywords: Dynamic pricing, Price multiplier, influencing variables

\section{INTRODUCTION TO DYNAMIC PRICING}

Dynamic pricing is a popular method of revenue management, especially when a firm needs to sell a given stock by deadline. Revenue management is a scientific method that helps firms to improve profitability of their business. The goal of dynamic pricing is to increase the revenue by discriminating customers who arrive at different times. For instance, if a firm faces a high level of demand, it has an incentive to increase the price to reserve some products for later customers who may be willing to pay more. On the other hand, if the demand is low the firm wishes to lower the price in order to induce the demand, because the product has no value (or very low value) after the deadline. Therefore, the retailer can dynamically adjust the price between any of a finite number of allowable prices (Richard Chatwin, 2000).

Dynamic pricing strategy often discounts excessive items, and charges a higher price for scarce items. A firm can often increase its revenue by carefully adjusting its product price over time.

The industry which is most commonly mentioned in terms of its adopting dynamic pricing strategies is airline transportation. Similarly, items such as hotel rooms, sports tickets, and seasonal fashion goods that become worthless if they are not sold by a specific time are all suited to dynamic pricing because these perishable items must be sold prior to the time at which they are unsalable. In all of these cases, the sellers can improve their revenue by dynamically adjusting the price of the perishable products rather than adopting a fixed price (Ue-Pyng Wenand Yen-Hsiang Chen, 2005).

By employing dynamic pricing, the act of changing prices over time within a marketplace, sellers have the potential to increase their revenue by selling goods to buyers "at the right time, at the right price."

\subsection{Revenue management}

\section{Background}

In the early 1970s, some airlines began offering restricted discount fare products that mixed discount and higher fare passengers in the same aircraft compartments. For example, BOAC (now British Airways) offered early bird bookings that charged lower fares to passengers who booked at least twenty- one days in advance of flight departure.

This innovation offered the airline the potential of gaining revenue from seats that would otherwise fly empty; however, it presented them with the problem of determining the number of seats that should be protected for late booking, full fare passengers. If too few seats were protected, the airline would spill full fare passengers; if too many were protected, flights would depart with empty seats.

No simple rule, like protecting a fixed percentage of capacity, could be applied across all flights because passenger booking behaviour varied widely with relative fares, itineraries, season, day of week, time of day, and other factors. It was evident that effective control of discount seats would require detailed tracking of booking histories, expansion of information system capabilities, and careful research and development of seat inventory control rules.

LITTLEWOOD (1972) of BOAC proposed that discount fare bookings should be accepted as long as their revenue value exceeded the expected revenue of future full fare bookings. This simple, two fare, seat inventory control rule (henceforth, Little 
wood's rule) marked the beginning of what came to be called yield management and, later, revenue management.

\subsection{Static and dynamic pricing}

Pricing is major area of airline revenue management. Pricing is generally categorized into two parts static and dynamic.

In the static pricing, the price is set at being of the booking period. In the dynamic pricing, the price changes throughout the booking period.

There is a trend in pricing that promises to significantly change the way goods are marketed and sold. Sellers now offer special deals, tailored for individual customers, and are beginning to compute the right price to the right customer at the right time. This change has been largely due to the wiring of the economy through the internet, corporate networks, and wireless networks. Buyers are now able to quickly and easily compare products and prices, putting them in a better bargaining position. At the same time, the technology is allowing sellers to collect detailed data about customers' buying habits, preferences, even spending limits, so they can customize their products and prices (Narahari, 2005).

In the past, there was a significant cost associated with changing prices, known as the menu cost. For a company with a large product line, it could take months for price adjustments to filter down to distributors, retailers, and salespeople. Emergence of network technology has reduced menu cost and time to near zero. As buyers and sellers interact in the electronic world, the resulting dynamic prices more closely reflect the true market value of the products and services being traded (Narahari, 2005).

\subsection{Dynamic pricing strategies}

Segmented Pricing refers to the customers' willingness to pay more for a given service or product. For example, a product may be sold at one price with a warranty and a lower price without a warranty.

Pricing based on peak times is peak user pricing. For example, airlines companies often charge a higher price to travel during rush hour on Monday through Friday than at other times and on weekends.

Service time is another dynamic pricing strategy is to charge more for faster service. For example, same-day dry cleaning would cost more than overnight cleaning.
Some dynamic pricing strategies offer customers different prices based on when they buy which are termed as time-based pricing. For example, the airline may try to fill seats by lowering the price as the day of the flight draws closer.

Based on the changing condition sellers can maximize profits by lowering prices as sales fall, then raising prices again as demand increases.

\subsection{Models used in dynamic pricing}

A variety of mathematical models have been used in computing dynamic prices. Most ofthese models formulate the dynamic pricing problem as an optimization problem. Dependingon the specific mathematical tool used and emphasized, we provide a list of five categories of models (Narahari, 2005).

Inventory-based models: These are models where pricing decisions are primarily based on inventory levels and customer service levels.

Data-driven models: These models use statistical or similar techniques for utilizing data available about customer preferences and buying patterns to compute optimal dynamic prices.

Game theory models: In a multi-seller scenario, the sellers may compete for the same pool of customers and this induces a dynamic pricing game among the sellers. Game theoretic models lead to interesting ways of computing optimal dynamic prices in such situations.

Machine learning models: An e-business market provides a rich playground for online learning by buyers and sellers. Sellers can potentially learn buyer preferences and buying patterns and use algorithms to dynamically price their offerings so as to maximize revenues or profits.

Simulation models: It is well known that simulation can always be used in any decision making problem. A simulation model for dynamic pricing may use any of the above four models stated above or use a prototype system or any other way of mimicking the dynamics of the system.

\subsection{Applications of dynamic pricing}

Dynamic pricing practices appear in industries where it is impossible (or very costly) to increase the inventory level and there exists a deadline to sell the products. These industries include fashion goods, airlines, hotel rooms, rental cars, and highway congestion control.

The vendor of fashion apparel, which perishes when the season ends, has to set its product price during the season. The consumers of the 
fashion goods enjoy more if they have the item in the earlier points of the season. For example, an air conditioner is more valuable at the beginning of the summer, so the consumers are willing to pay more in price earlier in summer. Using this fact, a retailer can potentially increase the revenue by charging a higher price at the beginning of the season and a lower price at the end of the season.

Airline industries often sell the airline tickets at a lower price to those consumers who buy their tickets early in advance, in order to reduce the risk of the airplane taking off with many vacant seats. If too many seats are sold at a low price, the airlines often would raise its ticket price, not only because the risk of having vacant seats is low but also because the airline wants to reserve seats for potential last-minute travellers.

The tourism industry is also one that makes frequent use of dynamic pricing. Different locations experience larger volumes of tourists at different times of the year. A beach resort, for instance, will experience much greater demand when it is summer in that location than it will during the winter, or if it is warm year-round at the beach resort, business might pick up when it is winter in other locations. Using dynamic pricing, a hotel will raise its prices during its peak season and lower them during the off-season.

Auction sites such as Ebay.com and Onsale.com have been successfully running auctions where people participate outbidding one another to purchase computers, electronics, sports equipment, etc. at dynamic prices that are governed by supplydemand characteristics.

\subsection{Merits and demerits of dynamic pricing}

Online dynamic pricing can help businesses in a variety of ways. It creates efficient markets by providing a mechanism to eliminate imperfect information, by increasing the geographic reach of smaller suppliers, and by streamlining purchasing processes.

By eliminating inefficiencies, suppliers are able to decrease costs and increase revenues on inventory, decrease overhead, eliminate costly middlemen, increase inventory turns, and create new.

In addition, dynamic pricing allows for "test pricing," and can yield increased revenue from new and unique items. All this is brought about through communities of buyers and sellers coming together to aggregate supply and demand. Internet Exchanges and auction technologies are creating a new class of intermediaries. These players create their own markets by inserting themselves into niches that previously had been dominated by entities offering only fixed-rate pricing, and offer advantages to both buyers and sellers in the process. The speed with which new companies can enter this space is increasing with the rollout of new auction applications that are faster and easier to implement.

Product pricing is one of the most important aspects of marketing that directly influences a business's ability to make profit and succeed. If a company sets prices too high, customers might choose to buy products elsewhere, while low prices may lead to a suboptimal amount of income. Dynamic pricing is a pricing method where businesses adjust prices based on consumer demand in an attempt to boost sales, which can potentially lead to several negative consequences.

\section{PRICING PRACTICES PREVALENT IN THE MARKET TODAY}

\subsection{Base price}

Base prices of the bus tickets are defined today based on the following factors:

- Travel distance

- Make of the bus

- $\quad$ Super luxury class - Includes Volvo, Mercedes and other top end buses

- Luxury class - Buses custom built on chassis of Tata/Leyland/Kinglongetc

- $\quad$ Climate control - A/C or Non A/C

- $\quad$ Seat Type - Push back, Semi sleeper (Push back seat with leg support), Sleeper (berths)

- $\quad$ Seat Layout - Number of seats in a row: $1+2,2+2$ etc

- $\quad$ Seat Position - Normally done for sleeper class buses. Lower berths are more comfortable than upper berths and hence many operators price them higher. Very rarely, a few operators price the rear seats lower than the front seats.

\subsection{Current practice of dynamic pricing}

Current practice of dynamic pricing is totally manual and might vary on both sides of the base price based on demand.

\subsubsection{Non peak days (supply>demand)}

Many operators lower their rates at boarding points and try to fill the buses. Lowering of rates is not done in their online sites or with the inventory available with aggregators.

Operators plying more than one bus in the same route consolidate their seats and ply lesser 
number of services. Single bus operators may cancel their service and consolidate their tickets with another operator plying in the same route or sometimes just refund the money to the customer.

Consolidation and cancelling of services depends on two conditions - The amount of cargo that is booked on their bus and the number of bookings that have already happened on the return trip.

\subsubsection{Peak days (demand $>$ supply)}

Many operators hike their fares based on their experience. Regular operators do not hike fares beyond a certain limit. Regular bus operators deploy all their spare buses on these dates at higher rates.

Special Bus operators (operators who lease buses and operate only on peak days) ply many services at very high rates depending on demand.

Special bus rates tend to be on the higher side due to the following factors:

- Demand is high and customers willing to buy tickets at a higher price

- $\quad$ Need for taking temporary permits for operating on specific days alone.

- $\quad$ On peak days, buses normally ply full only one way, i.e. from major metros to other destinations on the start of a holiday and in the reverse direction when the holidays or weekends is over. Operators will have to either ply the return trips empty or halt their buses in the destinations for the holiday period.

Few operators do not hike their fares even on peak days. Fare hike is based on the operators' previous experience. In recent days, we have seen many special bus operators quoting exorbitant rates only to revise them to a more reasonable level once they find that there are no takers at that price.

\section{DYNAMIC PRICING MODELUSING PRICE MULTIPLIERS}

The proposed dynamic pricing approach is based on having "price multipliers" and this idea was already validated for hotel revenue management problem by (Abd El-Moniem Bayoumi, 2001). These price multipliers provide a varying discount / premium over the base price. The base price is typically set by the bus operators.

Moreover, we have four multipliers that represent the "control variables". They will be multiplied by the base price, to obtain the final price. They vary around the value of 1 , where a value that is lower than one corresponds to a discount with respect to the base price (for example 0.9 means the price is $10 \%$ lower). Conversely, a value that is higher than 1 represents a premium over the base price.

The price multiplier values are determined based on analysis of price multipliers which affects the pricing decision. The advantage of this formulation is that it will give the bus operator a suggested price that has some relation with the price that he has determined during his experience. So, he can relate to the new price by observing its discount/premium in relation to his base price.

Each of the four multipliers corresponds to a variable that is known to have an influencing effect on pricing decisions. Specifically, the four variables that we selected are:

\section{Demand over departure time}

\section{Demand over months}

3. Booking rate variation over lead days (no. of days booked in advance)

\section{Filled rate for a bus over a period of time}

By determining the values of price multipliers final price can be calculated as shown in (1). Upper and lower limits for the price multipliers are set by the bus operators. By analysing demand over time, premium or discount over base price is applied.

The final price is given by the product of the reference price and the multipliers, as follows.

\section{Final price $=$ Base price*Departure time multiplier*Load multiplier*}

\section{Lead days multiplier*Filled rate multiplier (1)}

The resulting price will reflect the discounts/premiums resulting from the different values of the influencing variables.

\subsection{Price multipliers}

The following are the four multipliers that determine the final price:

\subsubsection{Departure time multiplier}

Departure time multiplier corresponds to the price influence of bus tickets based on the demand variation over different departure times available for the selected route. Each departure time for the selected route shows different demand and therefore discount can be applied for the price multiplier when the demand is low and premium can be applied for the price multiplier when the demand is high. i.e., Firm decreases the ticket price when demand is low and increases when demand is high. 


\subsubsection{Load multiplier}

Load multiplier corresponds to a price influencing variable which is based on the demand variation over seasons. Usually, holidays and summer seasons have high booking proportion. For e.g. April to May is a holiday season and therefore has high demand. So, firm increases the ticket price for high demand seasons and decreases price for lower demand seasons.

\subsubsection{Lead days multiplier}

Lead days are nothing but the number of days booked in advance before the departure date of a bus. Lead days multiplier corresponds to the price influence of ticket price based on the booking proportion over lead days. As per the analysis, booking proportion increases from seven days before the departure date.

Demand is very high on the day of travelling and low when booking starts from 20 days earlier before the departure date. Firm increases ticket price for customers booking in $0-7$ days before departure date.

\subsubsection{Filled rate multiplier}

Filled rate multiplier corresponds to the price influence based on filled proportion for a trip. Demand is high when the bus is at most filled (>90\%).During the high demand seasons buses have quick filling of seats. Therefore, Price is increased when filled rate is high and decreased when filled rate is low.

\section{DYNAMIC PRICING FOR ONLINE BUS TICKET BOOKING}

Dynamic pricing for online bus ticket booking is calculated using price multipliers: Departure time multiplier, Load multiplier, Lead days multiplier and Filled rate multiplier. Price multiplier values are determined from the analysis of price multipliers over demand and final price is obtained from the result (1).Demand corresponding to these price influencing factors varies according to the selected routes.

\subsection{Organisation profile}

The luxury bus industry today is worth 20,000 crores all over India. The four southern states will be contributing to around 5,000 crores to this market. Bus ticket pricing in the industry today is done manually by bus operators taking into consideration multiple factors and varies based on demand. Ticketgoose.com aims at devising a dynamic pricing mechanism which will allow operators define their prices dynamically taking into consideration the market factors.

\section{About Ticketgoose.com}

Ticket goose is promoted by Ticketgoose.com India Pvt. Ltd. and was launched in August 2007 is a ticketing web portal to provide online services to everyone travelling by bus. TicketGoose.com provides information like price, availability and booking facility for buses to over 5000 destinations and currently has $500+$ bus operators as partners.

Ticket goose.com's biggest advantage is its network of 3000+ channel partners who serve the customers without internet access. It is also a major supplier of inventory to other aggregation sites like Make My Trip, ixigo etc. Ticket goose. Com has been the torchbearer for organizing the hitherto unorganized bus industry in the country, by IT enabling operators with its unique and cost effective solutions. The Team at Ticketgoose.com, headed by Arun Athiappan, Co-Founder and CEO, comprises of highly qualified and dedicated technical professionals who are focused on ensuring hasslefree, cost effective and happy travel for all consumers who use its service.

\subsection{Case study}

Dynamic pricing is successfully tested for the route "CHENNAI- MUDALUR 2012". The data points were collected from Vahana operating network ofTicketgoose.com. Vahana operating network is one which includes own operators of Ticket goose.

\subsection{Route specifications}

Mudalur is located in Thoothukudi district. Travelling duration is around $11 \mathrm{hrs}$ and travelling distance is $654 \mathrm{kms}$. This route is a non-commercial route.

\subsection{Results from previous analysis}

For the selected route, demand over available departure times, season, lead days and Filled rate was analysed with the booking transactions for the year 2012 and the results are as follows:

\section{Departure Time Multiplier}

The Departure times available for the route are 16:00 hrs, 18:30 hrs, 19:15 hrs and 20:00 hrs. According to the analysis, demand is high for 19:15 hrs and low for 16:00 hrs. Premium over base price is given when demand is high and discount over base price is given when demand is low. As the selected 
route is a non-commercial route people wish the trip that would not affect their regular routines.

Travelling duration is around $11 \mathrm{hrs}$, so trip started at $19.15 \mathrm{hrs}$ will arrive at the destination by $6.15 \mathrm{hrs}$. $18.30 \mathrm{hrs}$ is having moderate demand.

\section{Load Multiplier}

Demand over seasons was analysed. According to the analysis, demand is high for May and June month and therefore premium over base price is given. Demand is low for November and December month and therefore discount over base price is given. Other seasons are having moderate demand.

\section{Lead Days Multiplier}

Booking rate is highly recorded on 7 days before departure date and very high on the day of travelling. Booking rate is very low for above 15 days booked in advance.Therefore, demand is very high on the day of travelling and so premium over base price is given. Discount over base price is given for lesser demand lead days.

\section{Filled Rate Multiplier}

Filled rate is higher on holiday and summer season and low on lesser demand conditions (for e.g. 15 days before departure, less preferred season).Premium over base price is given when filled rate is above $90 \%$ and discount over base price is given when bus is filled less than half.

\subsection{Dynamic pricing}

From the previous analysis and using the result (1) dynamic price for "Chennai-Mudalur" is calculated for higher, moderate and lower level of demands.

\subsubsection{Determining price multipliers}

Price multipliers vary around "1" where value lower than 1 corresponds to the discount over base price whereas value higher than 1 corresponds to the premium over base price.

\section{Table 1. Price Multiplier values}

\begin{tabular}{ll}
\hline \multicolumn{1}{c}{ Demand level } & \multicolumn{1}{c}{ Price multiplier values } \\
\hline High & $1.05-1.1(5-10 \%$ premium $)$ \\
Moderate & $0.96-1.04(1-4 \%$ discount \\
& or $1-4 \%$ premium $)$ \\
Low & $0.9-0.95(5-10 \%$ discount $)$ \\
\hline
\end{tabular}

Below are the price multiplier values determined from the analysis result.
Table 2. Price Multiplier values for Load Multiplier

\begin{tabular}{lll}
\hline \multicolumn{1}{c}{ Season } & \multicolumn{1}{c}{$\begin{array}{c}\text { Demand } \\
\text { level }\end{array}$} & $\begin{array}{c}\text { Price multiplier } \\
\text { values }\end{array}$ \\
\hline May, June, August & High & $\begin{array}{l}1.05-1.1(5- \\
10 \% \text { premium })\end{array}$ \\
January,April, July & Moderate & $\begin{array}{l}0.96-1.04(1- \\
4 \% \text { discount or }\end{array}$ \\
& & $1 \quad-\quad 4 \%$ \\
November, & & premium $)$ \\
December, & Low & $0.9-0.95(5-$ \\
February, & & $10 \%$ discount $)$ \\
March, September, & & \\
October & & \\
\hline
\end{tabular}

Table 3. Price Multiplier values for Departure Time Multiplier

\begin{tabular}{lll}
\hline Departure time & Demand level & $\begin{array}{c}\text { Price multiplier } \\
\text { values }\end{array}$ \\
\hline 19.15 & High & $1.05-1.1(5-$ \\
& & $10 \%$ premium $)$ \\
18.30 & Moderate & $0.96-1.04(1-$ \\
& & $4 \%$ discount or \\
& & $1-0 \quad 4 \%$ \\
16 & Low & $0.9-0.95 \quad(5-$ \\
& & $10 \%$ discount $)$ \\
\hline
\end{tabular}

Table 4. Price Multiplier values for Lead days Multiplier

\begin{tabular}{lll}
\hline Lead days & Demand level & $\begin{array}{c}\text { Price multiplier } \\
\text { values }\end{array}$ \\
\hline $0-7$ & High & $\begin{array}{l}1.05-1.1(5- \\
10 \% \text { premium })\end{array}$ \\
$7-15$ & Moderate & $0.96-1.04(1-$ \\
& $4 \%$ discount or \\
& & $1-4 \%$ premium $)$ \\
$15-60$ & Low & $0.9-0.95$ ( 5 - \\
& & $10 \%$ discount $)$ \\
\hline
\end{tabular}

Table 5. Price Multiplier values for Filled rate Multiplier

\begin{tabular}{cll}
\hline Filled rate & Demand level & $\begin{array}{c}\text { Price multiplier } \\
\text { values }\end{array}$ \\
\hline $70-97 \%$ & High & $\begin{array}{l}1.05-1.1(5- \\
10 \% \text { premium })\end{array}$ \\
$30-70 \%$ & Moderate & $0.96-1.04(1-$ \\
& & $4 \%$ discount or \\
& & $0.9-4 \%$ premium $)$ \\
$5-30 \%$ & Low & $10 \%$ discount $)$ \\
\hline
\end{tabular}




\subsubsection{Calculating dynamic price}

Final price is obtained as dynamic price which is the product of base price and price multipliers. Dynamic price for the selected route is calculated through MATLAB.

\section{Implementation Metho}

Price influencing booking details is taken as input. According to the inputs the demand level is obtained and final price is calculated with price multiplier values specified in the Tables $2,3,4 \& 5$.

In this method for the given level of demand, set of possible dynamic prices are calculated. Total price for the trip is also calculated automatically which gives convenience for the operators about selecting a dynamic price. Operator can select a dynamic price from a set of dynamic prices displayed and can be used for comparing with known revenue of the previous trip in which operator sold all tickets with different price.

Fig 1. Calculating possible dynamic prices for high demand (for 1 day booked in advance)

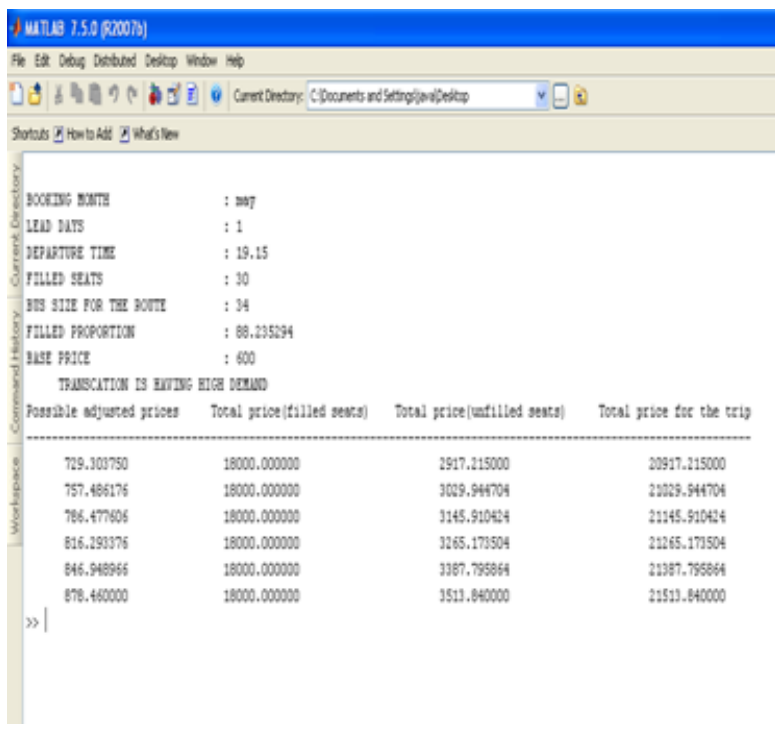

Fig 2. Calculating possible dynamic prices for high demand (for 2 day booked in advance)

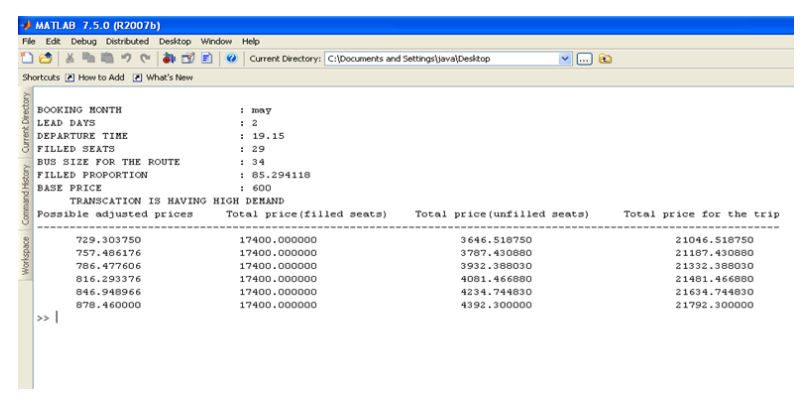

Fig 3. Calculating possible dynamic prices for moderate demand (for $\mathbf{1}$ day booked in advance)

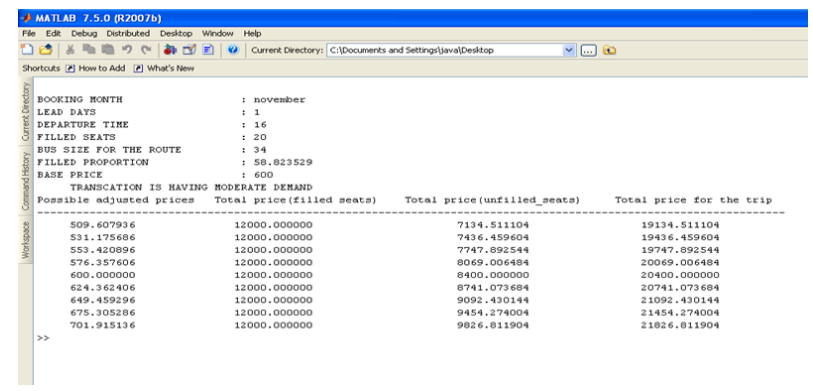

Fig 4. Calculating possible dynamic prices for moderate demand

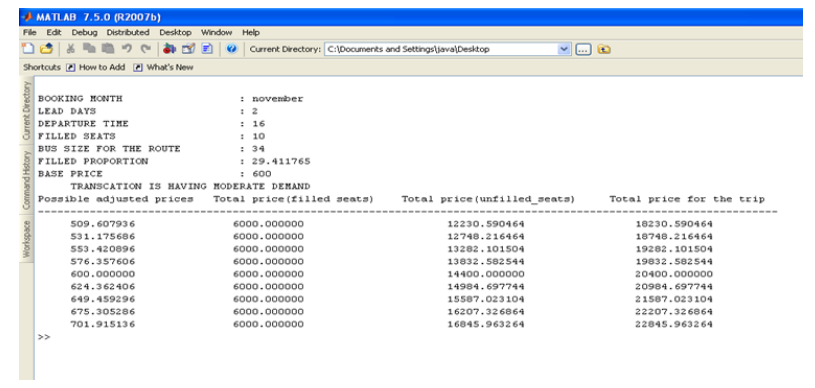

Fig 5. Calculating possible dynamic prices for lesser demand (for 10 days booked in advance)

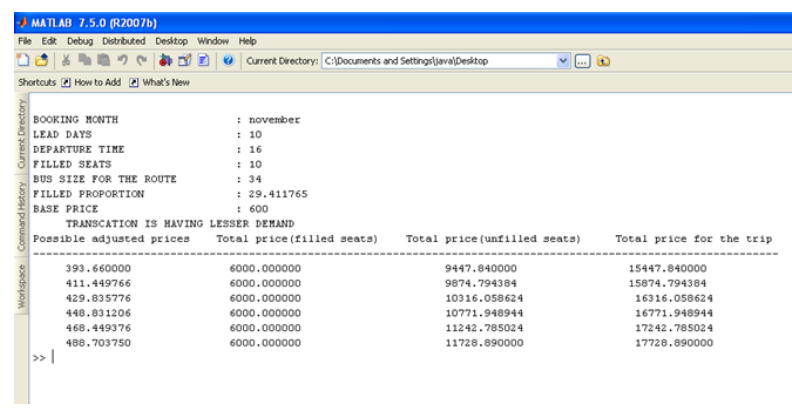

\section{CONCLUSION}

As bus ticket pricing in the industry today is done manually by bus operators taking into consideration multiple factors and varies based on demand. We aimed at devising a dynamic pricing mechanism which will allow operators define their prices dynamically taking into consideration the market factors.

With the drawbacks mentioned above, price multipliers approach for dynamic pricing is developed and values are determined from the previous analysis. Final price is calculated with the determined price multiplier values. This computation is implemented through MATLAB and successfully tested for the route "Chennai-Mudalur 2012". 
We firmly believe that a dynamic pricing approach will benefit both the customers and operators and hence will be immense value add to both.

\section{REFERENCES}

Abd El-Moniem Bayoumi, Mohamed Saleh, Amir Atiya \& Heba Abdel Aziz, (2011) Dynamic Pricingfor Hotel Revenue Management Using Price Multipliers, Egyptian Informatics Journal.
Narahari, Y., CVL. Raju, K. Ravikumar \& Sourabh Shah, (2005) Dynamic Pricing models for electronic business, Part 2 \& 3, 30: 231-256.

Richard Chatwin E, (2000), Optimal dynamic pricing of perishable products with stochastic demand and a finite set of prices, European Journal of Operational Research, 125: 149-174.

Ue-Pyng Wenand Yen-Hsiang Chen, (2005), Dynamic pricing model on the Internet Market, International Journal of Operations Research, 2(2): 72-80. 